LA-UR $-81-1725$

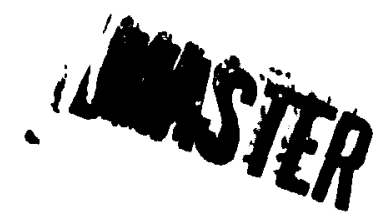

AUTHOR(S): J. N. Johnson

SUbmitted to: 1981 Toplcal Conference on Shock Waves in Condensed Matter, Menlo Park, CA, June 23-25, 1981 


\title{
CALCULATED SHOCK PRESSURES IN THE AQUARIUM TEST*
}

\author{
J. N. Johnson \\ Los Alamos National Laboratory, Los Alamos, NM 87545
}

\section{ABSTRACT}

A new method of analysis has been developed for determination of shock pressures in aquarium tests on comerclal explosives. This test consists of photographing the expanding cylindrical tube wall (which contains the detonation products) and the shock wave in water surrounding the explosive charge. By making a least-squares fit to the shock-front data, it is possible to determine the peak shockfront pressure as a function of distance from the cylinder wall. This has been done for $10-\mathrm{cm}$ and 20-cm-diam ANFO (amonium nitrate' fuel oil) and aluminlzed ANFO (7.5 wt\% Al) aquarlum test data.

\section{INTRODUCTION}

The aquarium test of explosive performance consists of optical measurement of detonation velocity, shock-wave position, and expansion rate of the pipe containing the tcst product. These experiments have been described 1 in a report by Cralg, et aj.1 The expansion of the tube wall glves information on the equation of otate of the detonation products, and this has been used to good advantage in determining the performance properties of ANFO. 1 The shock wave in water contains information on peak shock prassure delivered to the surrounding medium, and much less has been done with this information. The angle between the shock front and the cylinder axis 18 maximum at the pipe wall and monotonically decreases with increasing distance from the plpe wall. This is a consequence of higher shock pressures near the cavity wall and the dependence of shock velocity on compression. This informetion 1s used here to calculate pressure as a function of radius at the expanding shock front in number of ANFO and aluminized ANFO aquarium tests.

Explosive Initlation is soumed to take place at the top of a cylindrical column. In a downard-moving coordinate system travelIng with oteady detonation velocity $D$, the detonation wave appears to be ctationary, with material below flowing upward at valocity $D$, as shown in Fig. 1. The shock velocity at point $A$ is given by $U$. The unit normal and unit tangent vectore at point $A$ are $\hat{n}$ and $\hat{t}$, reopectively. If the shock wave in the water 1s oteady (that 18, unchanging in shape), it is al oo etationary in this coordinate aystem and the relatiunehip between $U$ and $D$ becomes

$$
U=D \cdot \sin e
$$

In this atacionury coordinate eyotem, material aheud of the shock is moving at velocity $-D$ in $\theta$ and $D \cos \theta$ relative to the $\hat{n}$ and $\hat{t}$ axes.

Work eupported by the U.S. Department of Energy.

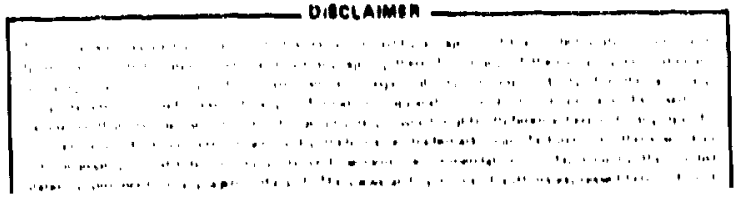




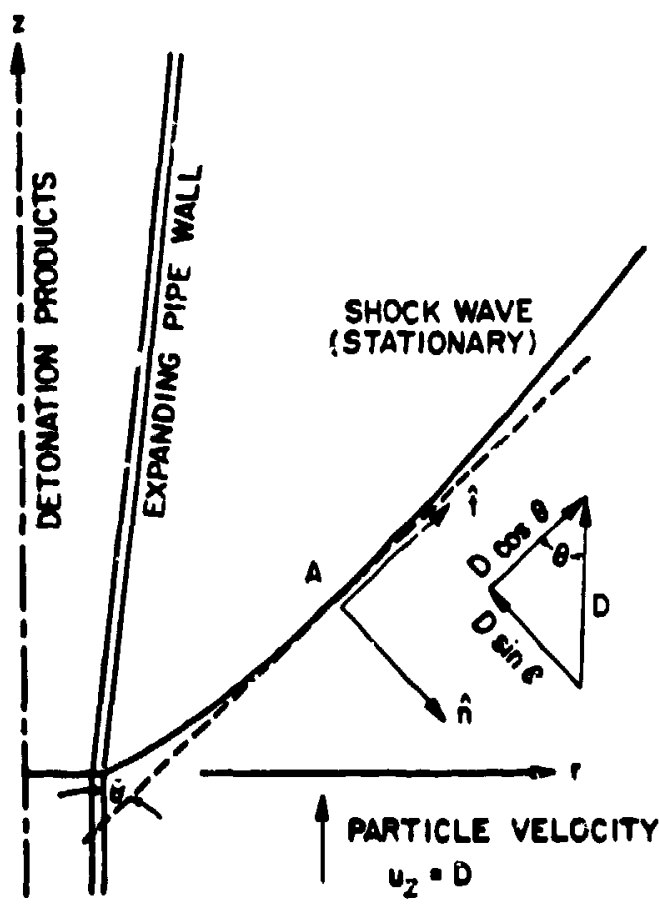

F18. 1. Stationary shock front and expanding plpe wall in coordinate system moving downward at velocity $D$.
The Rankine-Hugoniot jump cond 1 . tions for the cylindrically divergIng, curved shock front shown in F18. 1 can then be written as ${ }^{2}$

$$
\begin{aligned}
\rho u & =-\rho_{0} D \sin \theta, \\
v & =D \cos \theta, \\
p+\rho u^{2} & =\rho_{0} D^{2} \sin ^{2} \theta, \\
\left(u^{2}+v^{2}\right) / 2 & +e+p / \rho=D^{2} / 2,
\end{aligned}
$$

where $u$ and $v$ are velocity components in the $(\hat{n}, \hat{E})$ coordinate system, $\rho$ is the material density, $p$ is the pressure, and $e$ is the internal energy per unit mass, all evaluated behind the shock, and $P_{0}$ 18 the undisturbed density of the materlal ahead of the shock (at zoro pressure and zero internal energy). From Eqs. (2)-(5), the internal. energy change across the oblique shock of Fig. 1 is given by

$$
e=(p / 2)\left(1 / p_{0}-1 / p\right)
$$

which 18 exactly the same as that for a normal shock. Therefore, the p:essure-volume states for the otlique shock lie on the Hugoniot curve determined by one-dimensional plane shock-wave experimenta;

$$
p=\frac{\rho_{O} c_{w}^{2} \varepsilon}{(1-\varepsilon)^{2}}
$$

where $E \equiv 1-\rho_{0} / \rho_{0} . \rho_{0}-1.0 \mathrm{~B} / \mathrm{cm}^{3}, c_{w}=0.148 \mathrm{~cm} / \mu \mathrm{s}$ is the acoust1c (low amplitude sound) wave velocity in water, and $=2.0$ is the -lope of a etrajght-ling fit to the shock velocity-particle velocity data for water. ${ }^{3}$ From Equ. (2) and (4), it is found that

$$
P=\rho_{0} D^{2} \cdot \operatorname{tn}^{2} \theta c
$$

and hence, from Eqs. (7) and (8),

$$
p=\rho_{0} D^{2} \cdot \ln ^{2} \theta(1 / \theta)\left[1-c_{w} /(D \cdot \ln \theta)\right\} \text {, }
$$


which gives the pressure behind the shock wave when the steady detonation speed $D$ and the angle $\theta$ between the shock and the cylinder axis are knowr.

The argle $\theta$ is obtained from a fit of the shock front data to an expression of the form

$$
I=r_{0}+\tan \theta_{\min }\left[z+\frac{1}{a}\left(\frac{\tan \theta_{\max }}{\tan \theta_{\min }}-1\right)\left(1-e^{-a z}\right)\right],
$$

where

$$
\tan \theta_{\min }=\frac{C_{w} / D}{\sqrt{1-\left(c_{w} / D\right)^{2}}},
$$

and $a$ and $\tan \theta_{\max }$ are the two parsmeters determined by the method of least squares. 4 The angles $\theta_{\max }$ and $\theta_{\mathrm{m}}$ n have the physical interpretation of being the values of $\theta$ at $\left(z=0, r=r_{0}\right.$ ) and as $r$ (and $z$ ) $\rightarrow \infty$, respectively.

The expanding-pipe-wall data is fit to a linear expression of the form

$$
\mathbf{r}=\mathbf{r}_{0}^{\prime}+(\overline{\mathrm{V}} / \mathrm{D}) \mathbf{2},
$$

where $D$ 1s again the detonation speed, and $r_{0}^{\prime}$ and $\bar{v}$ are constants deternined by the method of least gquares. For a steacy propagating detonation (without change in shape of pipe wall or shock-front positions) in the negative $z-d i r e c t i o n$,

$$
r(z, t)=r_{0}^{\prime}+(\bar{v} / D)(z+D t),
$$

and the outward pipe velocity is giver by

$$
d r / d t=\bar{v} \text {. }
$$

Shock front and plpe-expaneion data for an aquarium teot on ANFO (Gulf N-C-N 100, Gulf O1l Chamicals Co., Mirian, Kansas) conteined In a 10-cm-1.d. clay plpe are shown in F1g. 2a along with the leastsquare f1ta; the ordinate in thie figure 1s $2 / D$, the time bahind the aseumed ateady propagating detonation front. The calculated ohork presalire as a function of radial position 1s shown in F18. 2b. A oummary of Init1 il density, detonation velocity, $\bar{v}$, and $P_{\text {wall }}$, the calculated shock pressure at the pipe vall, is given in Table I.

\section{DISCUSSION}

The calculated shock pressures at the pipe wall depend on In1t1al denelty and charge diameter, as expected. The effect of alum1nization on explosive performance 1o difficult to acceus from the data presented here, but remains an important one to try to quantify. 


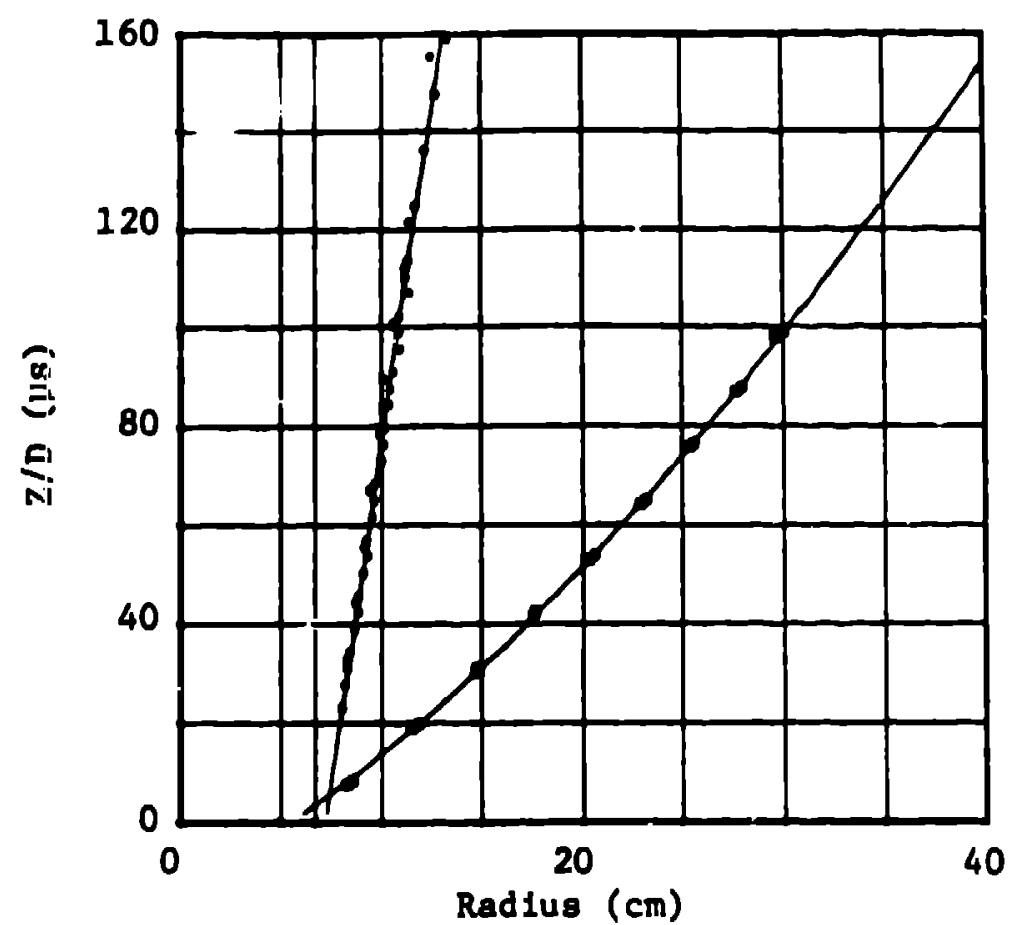

Fig. 2a. Shock front and pipe expansion data for aquarium test 4652 ( $p_{0}=0.90$ $\mathrm{g} / \mathrm{cm}^{3}$ ) with least-square fits (solid IInes).

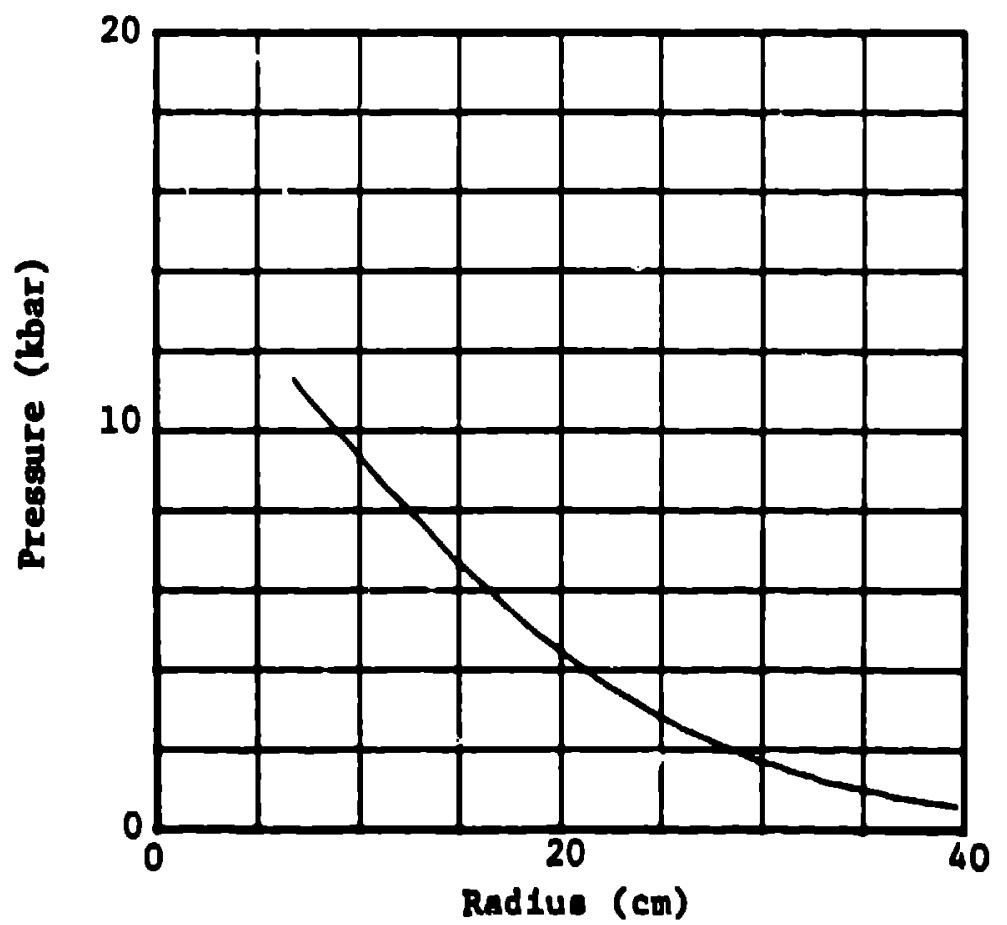

F18. 2b. Calculated ahock preasure at function of radial position. 
Table I. Summary of ANFO aquarlum tests: clay plpe confinement

\begin{tabular}{|c|c|c|c|c|c|}
\hline Experiment & $\begin{array}{c}\text { Diameter } \\
\text { (cm) }\end{array}$ & $\begin{array}{c}\rho_{0} \\
\left(8 / \mathrm{cm}^{3}\right)\end{array}$ & $\begin{array}{c}D \\
(\mathrm{~km} / \mathrm{s})\end{array}$ & $\begin{array}{c}\overline{\mathrm{V}} \\
(\mathrm{km} / \mathrm{s})\end{array}$ & $\begin{array}{l}P_{\text {wal1 }} \\
\text { (kbar) }\end{array}$ \\
\hline 4678 & 10 & 0.79 & 3.27 & 0.34 & 8.9 \\
\hline $4724^{\star}$ & 10 & 0.87 & 3.63 & 0.42 & 9.3 \\
\hline 4652 & 10 & 0.90 & 3.47 & 0.37 & 11.3 \\
\hline 4768 & 10 & 0.93 & 3.60 & 0.39 & 11.7 \\
\hline 4688 & 20 & 0.79 & 3.78 & 0.39 & 12.3 \\
\hline $4707^{\star}$ & 20 & 0.88 & 3.98 & 0.50 & 16.0 \\
\hline 4664 & 20 & 0.90 & 4.12 & 0.43 & 15.0 \\
\hline 4700 & 20 & 0.90 & 4.15 & 0.47 & 15.8 \\
\hline $4752^{\star}$ & 20 & 1.11 & 4.24 & 0.51 & 19.5 \\
\hline
\end{tabular}

Experimental work 18 continuing on the actual time-resolved measurement of shock pressures for well characterized aluminized ANFO explosives. Combination of these measurementa with the analysis presented here will provide a check on data consistency as well as unambiguous information on the role of aluminum in improving explosive performance.

\section{REFERENCES}

1. B. G. Cra1B, J. N. Johnwon, C. L. Macer, and C. F. Lederman, "Characterization of Two Comerclal Explosives," Los Alamos Sclent1fic Laboratory report LA-7140 (May 1978).

2. L. D. Landau and E. M. Lifehitz, Fluld Mechanics (Pergamon Press, London, 1959), FP. 317-319.

3. S. P, Marsh, LASI Shock Huronlot Data (Univers1ty of Cal1fornia Prewe, Berkeley, 1980), PP. 573-574.

4. H. Margenau and G. M. Murphy, The Mathemat1ce of Physice and Chempetry (D. Van Noetrand Co., Inc., PrInceton, 1956), PP. 517S18. 